\title{
The Influence of Metal Carbides on the Oxidation Processes of 1-Octene by Molecular Oxygen and tert-Butyl Hydroperoxide
}

\author{
Oksana Makota and Lidiya Bulgakova \\ Institute of Chemistry and Chemical Technologies, Lviv Polytechnic National University, 12 S. Bandera Street, Lviv 79013, Ukraine \\ Correspondence should be addressed to Oksana Makota, makotaoksana@yahoo.com
}

Received 26 August 2011; Accepted 5 October 2011

Academic Editor: J. Mavri

Copyright () 2012 O. Makota and L. Bulgakova. This is an open access article distributed under the Creative Commons Attribution License, which permits unrestricted use, distribution, and reproduction in any medium, provided the original work is properly cited.

The influence of metal carbides, $\mathrm{TiC}, \mathrm{VC}, \mathrm{ZrC}, \mathrm{Mo}_{2} \mathrm{C}, \mathrm{TaC}$, and $\mathrm{WC}$, on the liquid-phase oxidation processes of 1-octene by molecular oxygen and tert-butyl hydroperoxide was investigated. It was established that vanadium carbide is the most active in the oxidation process of 1-octene by molecular oxygen as well as in the tert-butyl hydroperoxide unproductive decomposition process in the hydroperoxide oxidation reaction. It was shown that there is a correlation among the activities of metal carbides in these processes.

\section{Introduction}

The oxidation of saturated and unsaturated hydrocarbons with different oxidants is one of the most important, promising, and challenging fields from both, academic and industrial points of view $[1,2]$. This process allows to obtain epoxides, diols, ketones, and other oxygen-containing compounds which are key materials for synthesis of fine chemicals, pharmaceuticals, and important intermediates in petroleum industrial chemistry [3-5].

Among the commonly used oxidants, molecular oxygen has attracted a great deal of attention [6]. This oxidant is cheaper, safer, and greener and has a higher content of active oxygen than others. However, the technology with which oxidation substrates are oxidized by molecular oxygen to produce desirable products has not been improved very well up to now. In many cases, the direct oxidation of organic substrates by molecular oxygen with desirable products formation usually required an initiator (additional organic solvent and hydrogen peroxide or alkyl hydroperoxide) as well as effective catalyst which plays a central role in the oxidation process.

Complexes of various transition metals are used as the homogeneous catalysts in the oxidation of saturated and unsaturated hydrocarbons by molecular oxygen $[7,8]$. However, the separation and recycling of the homogeneous catalysts are, in general, very difficult, and therefore, production of toxic waste is unavoidable. That is why, efforts are being made to search for simple and inexpensive but easily separable and reusable heterogeneous catalysts [9-11].

In the present work, the activity of heterogeneous transition metal carbides: $\mathrm{TiC}, \mathrm{VC}, \mathrm{ZrC}, \mathrm{Mo}_{2} \mathrm{C}, \mathrm{TaC}$, and $\mathrm{WC}$ in the liquid-phase oxidation processes of 1-octene (OC) by molecular oxygen and tert-butyl hydroperoxide (TBHP) was investigated.

\section{Experimental}

Commercial 1-octene of reagent pure grade was additionally distilled. Commercial solvent chlorobenzene, chemically pure grade, was additionally dried and distilled. The metal carbides (Cat): $\mathrm{TiC}, \mathrm{VC}, \mathrm{ZrC}, \mathrm{Mo}_{2} \mathrm{C}, \mathrm{TaC}$, and $\mathrm{WC}$ were commercial chemicals of chemically pure grade. Molecular oxygen was purified prior to entering the reaction system, and it was passed through $\mathrm{CaCl}_{2}$ and mixture of $\mathrm{CaO}$ and $\mathrm{NaOH}$. tert-Butyl hydroperoxide was synthesized from tertbutyl alcohol and hydrogen peroxide in the presence of sulfuric acid by the procedure [12]. Azodiizobutyronitrile (AIBN) was purified by recrystallization from ethanol.

The oxidation process of 1-octene by molecular oxygen was carried out in a glass reactor equipped with a magnetic 
stirrer and constant temperature jacket at gasometric unit [13] at temperature $353 \mathrm{~K}$ and $1 \times 10^{5} \mathrm{~Pa}$ of oxygen pressure.

The oxidation of 1-octene by TBHP was realized in thermostated glass reactor fitted with a magnetic stirrer and a reflux condenser under an argon atmosphere at temperature $393 \mathrm{~K}$, but in the case of $\mathrm{Mo}_{2} \mathrm{C}$, temperature was $363 \mathrm{~K}$ (because of high activity of this carbide in this process).

The rate of 1-octene oxidation process by molecular oxygen was determined from the rate of oxygen absorption. It was established that the oxidation rate does not depend on the oxygen pressure when pressure is higher than $5 \times 10^{4} \mathrm{~Pa}$.

The rate of the oxidation process of 1-octene by TBHP was determined from kinetic curves for hydroperoxide consumption. The hydroperoxide content was determined by iodometric titration. The reaction mixtures were analyzed by gas chromatography using a Tsvet-100 gas chromatograph with a thermal conductivity detector. The reaction mixtures were separated into components on a column of $3 \mathrm{~m}$ length and $4 \mathrm{~mm}$ diameter packed with $10 \%$ Apiezon L on Chromaton N-AW, at $413 \mathrm{~K}$ and carrier gas (hydrogen) flow rate $3.6 \mathrm{~L} / \mathrm{h}$.

\section{Results and Discussion}

It was established that purified and distilled 1-octene is not oxidized by molecular oxygen in the presence of transition metal carbides under these reaction conditions for 2 hours. That is why the homogeneous initiators of radical processes: AIBN, TBHP were introduced in the reaction system and the liquid-phase oxidation process was carried out in similar conditions.

It was observed that introduction of AIBN in the reaction mixture leads to the increase in the oxygen consumption. However, the introduction of metal carbides in the reaction system in the presence of AIBN has no result: the oxidation rate is the same as for the noncatalytic process. It shows that metal carbides do not influence the liquid-phase oxidation process when AIBN is present in the reaction mixture.

When another homogeneous initiator, TBHP, was used instead of AIBN, the character of metal carbides influence on the process changed. The introduction of metal carbides in the reaction system results in increasing the oxidation rate which depends on metal nature in carbides. It indicates the activated influence of metal carbides on the oxidation process of 1-octene by molecular oxygen in the presence of TBHP.

This influence of metal carbides on the oxidation process in the presence of AIBN and TBHP allows to conclude that these catalysts do not influence chain propagation and chain termination stages. The effect of metal carbides on the oxidation process of 1-octene by molecular oxygen is to deal with participation in the stage of radical formation by TBHP decomposition.

The obtained results of the influence of metal carbides on the liquid-phase oxidation process of 1-octene by molecular oxygen in the presence of tert-butyl hydroperoxide in the reaction system are presented in Figure 1. It is seen that the most intensive oxygen absorption in the oxidation process is observed in the presence of VC. It indicates that this carbide is the most active in the investigated process. Other metal

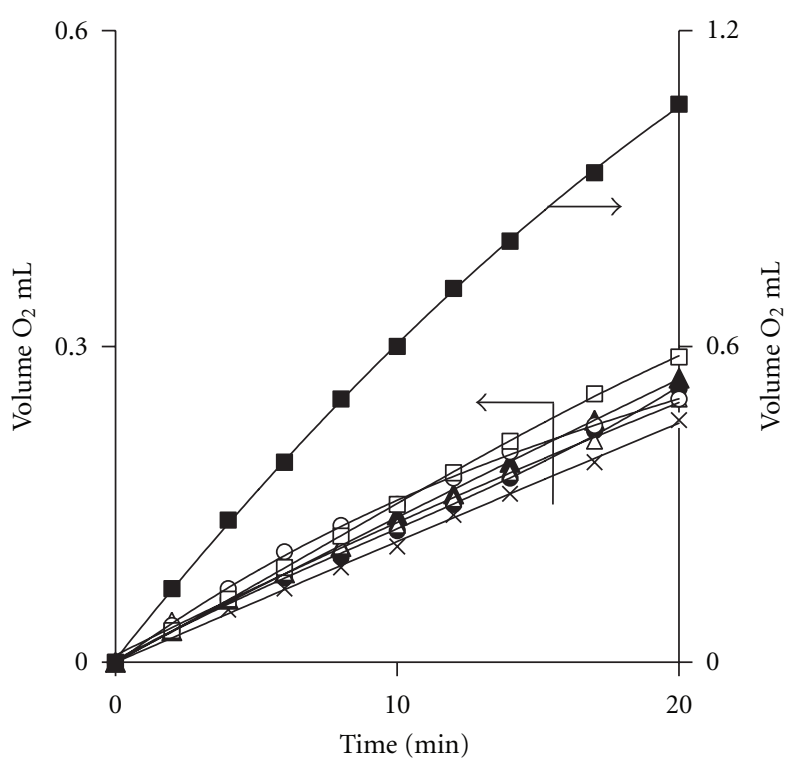

Figure 1: The kinetic curves for the oxygen absorption in the oxidation process of 1-octene by molecular oxygen in the presence of metal carbides: $\mathrm{ZrC}(\boldsymbol{\Delta}), \mathrm{VC}(\mathbf{\square}), \mathrm{Mo}_{2} \mathrm{C}(\bigcirc)$, WC $(\square), \mathrm{TaC}(\Delta)$, and $\mathrm{TiC}(\bullet)$ and without catalyst $(\times)$. $\left.[\mathrm{OC}]_{\mathrm{o}}=5.7 \mathrm{~mol} /{ }, \mathrm{TBHP}\right]_{\mathrm{o}}=$ $0.05 \mathrm{~mol} / \mathrm{L}$, $[$ Cat $]=3 \mathrm{~g}^{2} / \mathrm{L}$, and $T=353 \mathrm{~K}$.

carbides slightly speed the oxidation process in compare with the noncatalytic process. One can conclude that they exhibit unsignificant activated influence on the oxidation process.

Taking into account the obtained results and based on data of literature $[14,15]$ as well as data of our previous works [16-18], we can propose the next model of the radical formation process in the oxidation process of 1-octene by molecular oxygen in the presence of metal carbides and TBHP on the initial stages of the reaction

$$
\mathrm{TBHP}+\mathrm{TBHP} \underset{k_{-1}}{\stackrel{k_{1}}{\rightleftarrows}} \mathrm{Z}_{1}, \quad \mathrm{Z}_{1}+\mathrm{Cat} \underset{k_{-2}}{\stackrel{k_{2}}{\rightleftarrows}} \mathrm{Z}_{2},
$$

where $Z_{1}$-complex between two TBHP molecules; $Z_{2}$ complex of catalyst with two molecules of TBHP.

The radicals are formed in the following reactions:

$$
\begin{gathered}
\mathrm{Z}_{1} \stackrel{k_{n \mathrm{Cat}}}{\longrightarrow}\left(\mathrm{CH}_{3}\right)_{3} \mathrm{CO}^{\circ}+\left(\mathrm{CH}_{3}\right)_{3} \mathrm{COO}^{\circ}+\mathrm{H}_{2} \mathrm{O}, \\
\mathrm{Z}_{2} \stackrel{k_{\mathrm{Cat}}}{\longrightarrow}\left(\mathrm{CH}_{3}\right)_{3} \mathrm{CO}^{-}+\left(\mathrm{CH}_{3}\right)_{3} \mathrm{COO}^{\circ}+\mathrm{H}_{2} \mathrm{O}+\mathrm{Cat}^{\circ}
\end{gathered}
$$

where $k_{n \text { Cat }}-$ rate constant of reaction of noncatalytic radicals formation; $k_{\text {Cat }}-$ rate constant of radicals formation reaction in the presence of catalyst.

The overall scheme of the oxidation process of olefins by molecular oxygen in the presence of catalysts and TBHP on the initial stages of the reaction is described in [16-18].

It is also interesting to study the activity of metal carbides in the liquid-phase oxidation process of 1-octene tert-butyl hydroperoxide in the absence of molecular oxygen in atmosphere of inert gas and argon and to compare the influence of carbides on the oxidation processes of 1-octene by molecular oxygen and TBHP. 


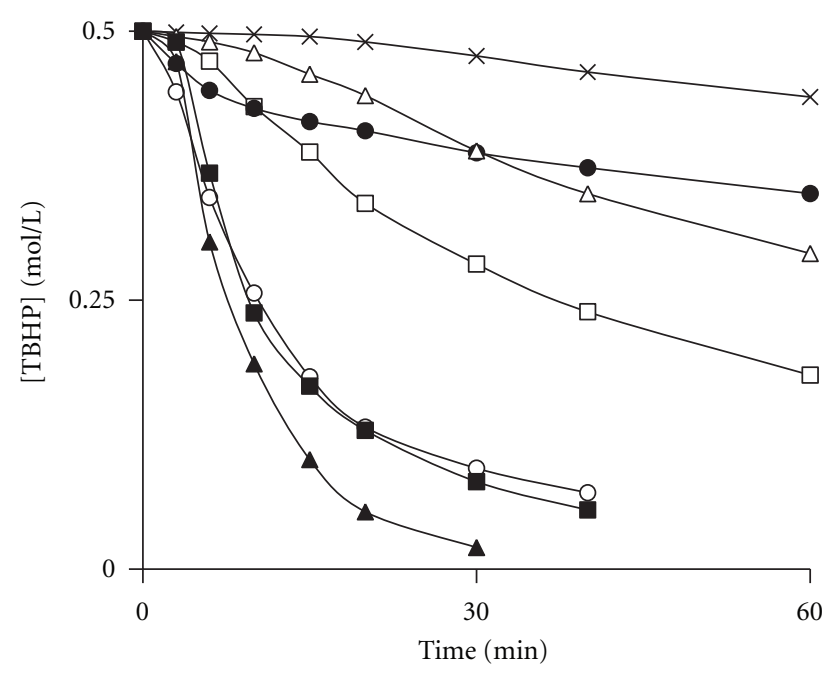

FIGURE 2: The kinetic curves for TBHP consumption in the oxidation process of 1-octene by TBHP in the presence of metal carbides: $\operatorname{ZrC}(\boldsymbol{\Delta}), \mathrm{VC}(\boldsymbol{\square}), \mathrm{Mo}_{2} \mathrm{C}(\bigcirc)$, WC $(\square), \mathrm{TaC}(\Delta)$, and $\mathrm{TiC}(\bullet)$ and without catalyst $(\times)$. $[\mathrm{OC}]_{\mathrm{o}}=2.5 \mathrm{~mol} /,[\mathrm{TBHP}]_{\mathrm{o}}=$ $0.5 \mathrm{~mol} / \mathrm{L}$, [Cat] $=3 \mathrm{~g}^{2} / \mathrm{L}$, and $\mathrm{T}=393 \mathrm{~K}$ (in the presence of $\mathrm{Mo}_{2} \mathrm{C}$ $T=363 \mathrm{~K})$.

Figure 2 presents the proceeding of the hydroperoxide oxidation process of 1 -octene in the presence of metal carbides in inert atmosphere.

One can see that all investigated carbides increase the TBHP consumption in comparison to the noncatalytic process which occurs slightly. However, their catalytic activity is different. $\mathrm{Mo}_{2} \mathrm{C}, \mathrm{ZrC}$, and $\mathrm{VC}$ are the most active in the process of TBHP consumption in the reaction of the 1-octene hydroperoxide oxidation, whereas $\mathrm{TiC}$ and $\mathrm{TaC}$ show, lowest activity. Tungsten carbide exhibits intermediate catalytic activity in this process. It is established that in the presence of all the investigated metal carbides, the 1,2epoxyoctane is formed with the selectivity of (in account of hydroperoxide consumption) $81,96,84,43,22$, and $20 \%$ in the presence of $\mathrm{Mo}_{2} \mathrm{C}, \mathrm{ZrC}, \mathrm{VC}, \mathrm{WC}$, and $\mathrm{TiC}$, respectively, and $1 \%$ in the absence of catalyst in the reaction system.

The obtained results indicate the significant contribution of unproductive TBHP consumption in the overall 1octene hydroperoxide oxidation process especially in the presence of $\mathrm{TaC}$ and VC. Therefore, the values of initial rate of the hydroperoxide unproductive decomposition process $\left(R_{\mathrm{dec}}\right)$ were calculated from the overall initial rate of the hydroperoxide oxidation process of 1-octene by TBHP using the values of contribution of hydroperoxide decomposition reaction (Figure 3 ). The values of initial rate of the oxidation reaction by molecular oxygen in the presence of TBHP $\left(\mathrm{RO}_{2}\right)$ are also given in this figure.

It is seen that in the case of vanadium carbide, the initial rate of the oxidation reaction by molecular oxygen as well as the initial rate of the hydroperoxide unproductive decomposition process in the hydroperoxide oxidation reaction reached its highest value. Figure 3 shows that the character of change in the rate of oxidation reaction of 1octene by molecular oxygen with change of metal nature

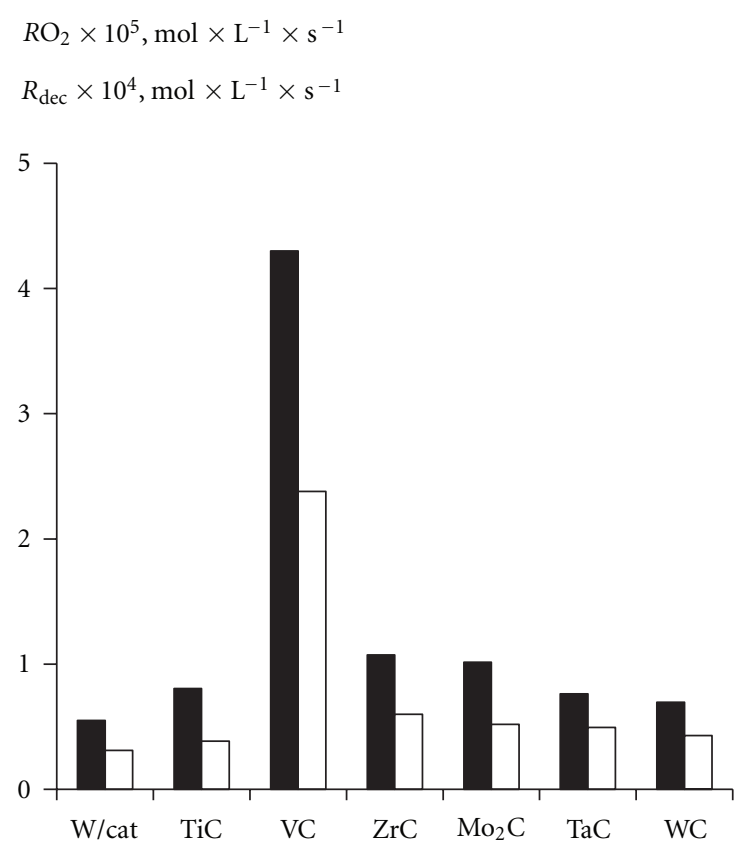

FIgUre 3: The dependence of the initial rates of the TBHP unproductive decomposition process in the hydroperoxide oxidation reaction (filled columns) and the oxidation process of 1-octene by molecular oxygen (open columns) on metal nature in catalyst.

of carbides correlates with the character of change in the rate of hydroperoxide unproductive decomposition process in the reaction of oxidation of 1-octene by tert-butyl hydroperoxide.

Thus, the obtained results show that there is correlation between the activity of metal carbides in the processes of oxidation of 1-octene by molecular oxygen and their activity in the hydroperoxide unproductive decomposition process in the reaction of oxidation of 1-octene by tertbutyl hydroperoxide. The highest value of the initial rate for both the oxidation reaction by molecular oxygen and the hydroperoxide unproductive decomposition process is achieved in the presence of vanadium carbide. The investigated metal carbides take part in the oxidation process of 1-octene by molecular oxygen in the presence of TBHP via catalythis of reaction of radical formation by radical decomposition of tert-butyl hydroperoxide.

\section{References}

[1] W. Adam, Ed., Peroxide Chemistry. Mechanistic and Preparative Aspects of Oxygen Transfer, Wiley-VCH, Weinheim, Germany, 2000.

[2] K. Weissermel and H.-J Arpe, Industrial Organic Chemistry, Wiley-VCH, Weinheim, Germany, 2003.

[3] J. Marco-Contelles, M. T. Molina, and S. Anjum, "Naturally occurring cyclohexane epoxides: Sources, biological activities and synthesis," Chemical Reviews, vol. 104, no. 6, pp. 28572899, 2004.

[4] A. K. Yudin, Aziridines and Epoxides in Organic Synthesis, Wiley-VCH, Weinheim, Germany, 2006. 
[5] D. Díez, M. T. Beneitez, I. S. Marcos, N. M. Garrido, P. Basabe, and J. G. Urones, "Regio- and stereoselective ring opening of epoxides. Enantioselective synthesis of 2,3,4-trisubstituted five-membered heterocycles," Tetrahedron Asymmetry, vol. 13, no. 6, pp. 639-646, 2002.

[6] C. L. Hill, "Controlled green oxidation," Nature, vol. 401, no. 6752, pp. 436-437, 1999.

[7] K. A. Jørgensen, "Transition-metal-catalyzed epoxidations," Chemical Reviews, vol. 89, no. 3, pp. 431-458, 1989.

[8] R. A. Sheldon, "Synthetic and mechanistic aspects of metalcatalysed epoxidations with hydroperoxides," Journal of Molecular Catalysis, vol. 7, no. 1, pp. 107-126, 1980.

[9] Q. H. Xia, H. Q. Ge, C. P. Ye, Z. M. Liu, and K. X. Su, "Advances in homogeneous and heterogeneous catalytic asymmetric epoxidation," Chemical Reviews, vol. 105, no. 5, pp. 16031662, 2005.

[10] B. K. Hodnett, Heterogeneous Catalytic Oxidation. Fundamental and Technological Aspects of the Selective and Total Oxidation of Organic Compounds, John Wiley \& Sons, New York, NY, USA, 2000.

[11] I. W. C. E. Arends and R. A. Sheldon, "Activities and stabilities of heterogeneous catalysts in selective liquid phase oxidations: recent developments," Applied Catalysis A, vol. 212, no. 1-2, pp. 175-187, 2001.

[12] N. A. Milas and D. M. Surgenor, "Studies in organic peroxides. VIII. t-Butyl hydroperoxide and di-t-butyl peroxide," Journal of the American Chemical Society, vol. 68, no. 2, pp. 205-208, 1946.

[13] V. F. Tsepalov, "Automatic equipment for measurement of consumption of low quantities of gas," Zavodskaya Laboratoriya, vol. 1, pp. 111-112, 1964.

[14] E. T. Denisov and I. B. Afanas'ev, Oxidation and Antioxidation in Organic Chemistry and Biology, Taylor and Francis, Boca Raton, Fla, USA, 2005.

[15] L. R. C. Barclay and K. U. Ingold, "Autoxidation of biological molecules. 2. The autoxidation of a model membrane. A comparison of the autoxidation of egg lecithin phosphatidylcholine in water and in chlorobenzene," Journal of the American Chemical Society, vol. 103, no. 21, pp. 6478-6485, 1981.

[16] Y. B. Trach and O. I. Makota, "Specifics of oxidation of octene1 with molecular oxygen on vanadium disilicide," Petroleum Chemistry, vol. 49, no. 5, pp. 393-396, 2009.

[17] Y. B. Trach, L. V. Bulgakova, O. I. Makota, W. Y. Suprun, B. Schulze, and C. B. W. Stark, "Vanadium diboride catalyzed oxidation of cyclooctene by molecular oxygen: Kinetic study," Journal of Molecular Catalysis A, vol. 302, no. 1-2, pp. 124-128, 2009.

[18] O. Makota, Y. Trach, R. Leboda, and J. Skubiszewska-Zieba, "The study of cyclooctene oxidation with molecular oxygen catalyzed by VSi2," Central European Journal of Chemistry, vol. 7, no. 4, pp. 731-738, 2009. 


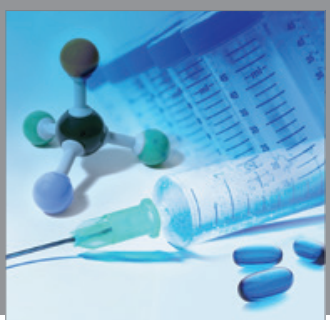

International Journal of

Medicinal Chemistry

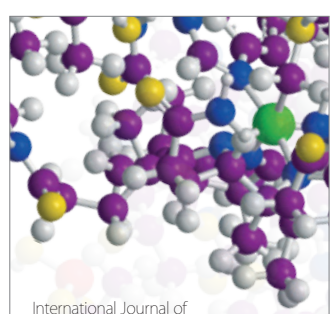

Carbohydrate Chemistry

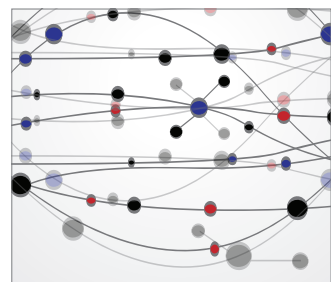

The Scientific World Journal
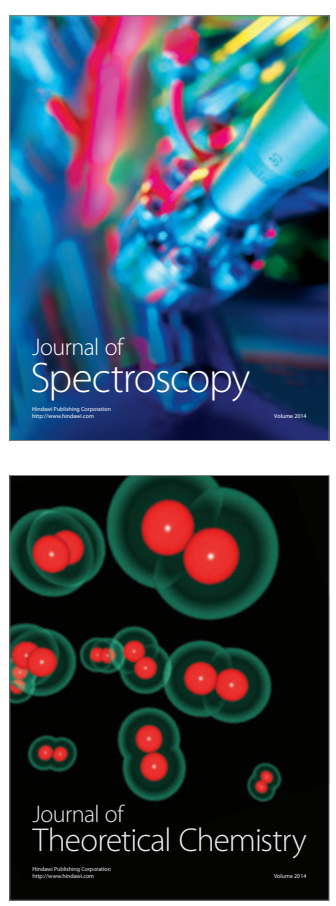
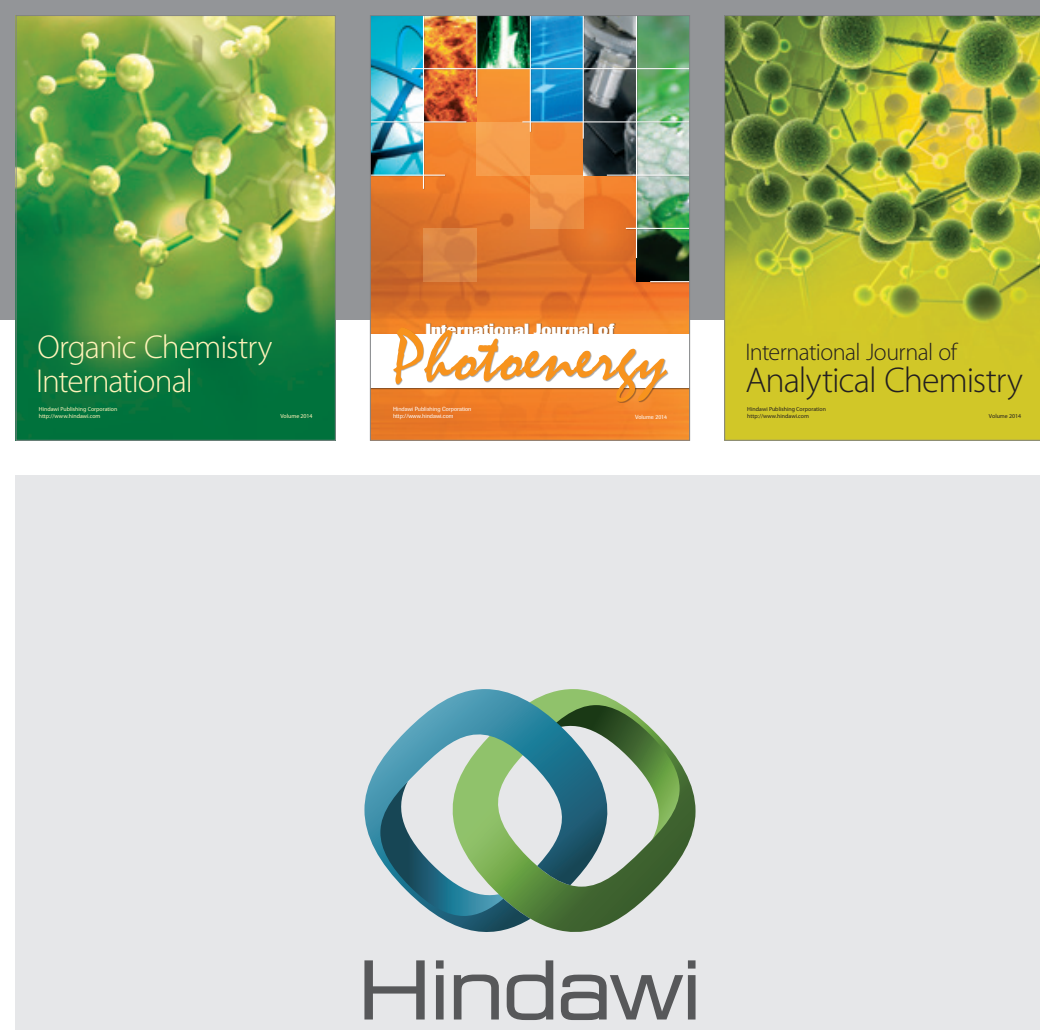

Submit your manuscripts at

http://www.hindawi.com
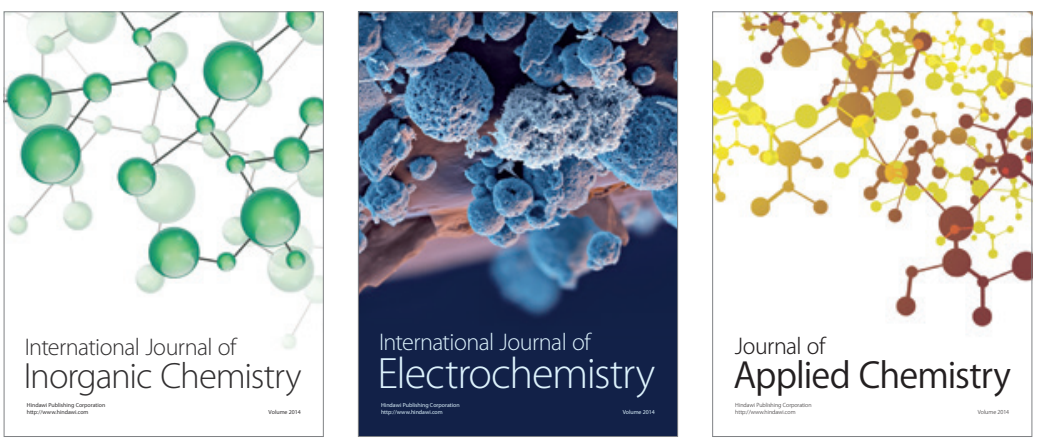

Journal of

Applied Chemistry
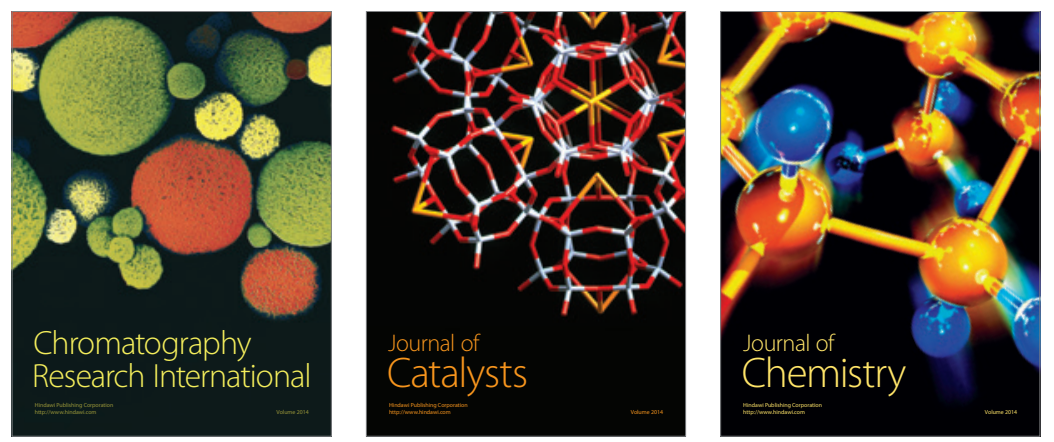
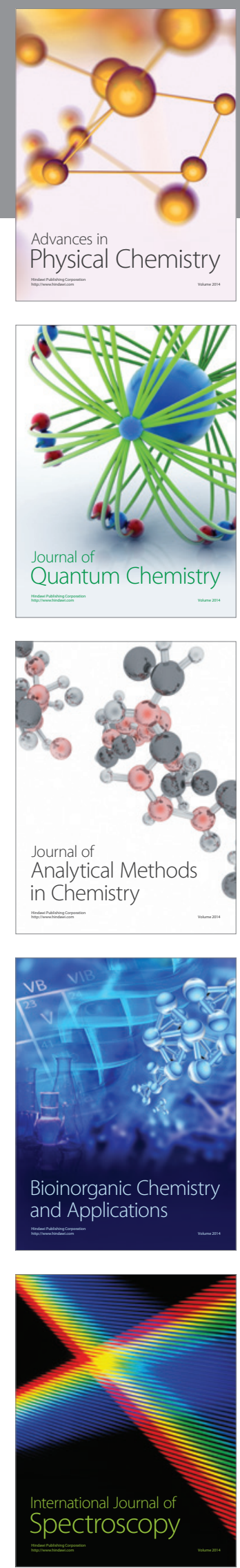